\title{
Mung Bean Rhizobacteria Antagonist to Fusarium oxysporum and Rhizoctonia solani
}

\section{Oberai ${ }^{1 *}$ and V Khanna ${ }^{2}$}

${ }^{1}$ Department of Microbiology, Punjab Agricultural University, Ludhiana, India

${ }^{2}$ Department of Plant Breeding and Genetics, Punjab Agricultural University, Ludhiana, India

*Corresponding Author: M Oberai, Department of Microbiology, Punjab Agricultural University, Ludhiana, India.

Received: July 08, 2019; Published: July 12, 2019

DOI: 10.31080/ASMI.2019.02.0307

\begin{abstract}
Rhizobacterial chemicals can prove to be dynamic natural pesticides. In the present study twelve PGPR isolates from mung-bean rhizosphere showed ability to produce various volatile and non-volatile chemicals such as Hydrogen cyanide, siderophore, volatile antifungal compounds, diffusible antimetabolites (viz. pyrrolnitrin, cyclic lipopeptides), ammonia, hydrolytic enzymes and phenazine which had a biocidal effect on Fusarium oxysporum and Rhizoctonia solani. The TLC and HPLC analysis confirmed the production of phenazine by Isolate MO33. The crude filtered extract containing phenazine had anti-mycotic potential against the test pathogens. SEM analysis of the antagonist-pathogens post interaction events showed a biocidal effect on fungal hyphae brought about by these bacterial chemicals, showing scanty, deflated, perforated and shrunken hyphae.
\end{abstract}

Keywords: Hydrogen Cyanide; Hydrolytic Enzymes; Phenazine; SEM Studies; Siderophore; Volatiles

\section{Introduction}

Mung bean (Vigna radiata), known as green gram or golden gram, is one of the most important short duration pulse crops grown in India during the kharif, spring and summer seasons. However, its production and productivity has been stationary as the crop is prone to more than one disease and pests [34]. Fungi such as Fusarium spp., Rhizoctonia solani, Macrophomina phaseolina and Pythium spp., produce severe diseases such as root rot, charcoal rot, damping-off and stem rot as well as mycotoxins in the grain $[4,26]$. These soil-borne pathogens can be controlled by chemicals but use of the chemical pesticides has several negative effects. The use of microbial antagonists is a safe, effective and eco-friendly method for the control of many of these soil-borne pathogens and this is gaining popularity in recent days. These biological agents promote plant growth by nutrient recycling and other processes [30]. Their biocidal effects can occur via local antagonism to soil-borne pathogens or by induction of systemic resistance against pathogens. Several substances produced by antagonistic rhizobacteria have been tested for pathogen control and indirect promotion of growth in many plants [6].
Induced systemic resistance (ISR) in plants bears a resemblance to pathogen-induced systemic acquired resistance (SAR) under conditions where the inducing bacteria and the challenging pathogen remain spatially separated. Both types of induced resistance allow the uninfected plant more resistance to pathogens. Rhizobacteria belonging to the genera Pseudomonas and Bacillus are well known for their antagonistic effects and their ability to trigger ISR [6]. Resistance-inducing and antagonistic rhizobacteria might be beneficial in formulating new inoculants with combinations of different mechanisms of action, leading to a more efficient use for biocontrol strategies.

Some successful applications of rhizobacteria have been reported by in-vitro assays, green house experiments and field trials [26]. Although the exact mechanism of their action is not known, it is believed that these bacteria secrete antimicrobial substances such as siderophores, HCN, salicylic acid, antibiotics and cyclic lipopeptides (LPs) which act as bioactive metabolites and are effective in controlling diseases [4,27]. Many investigators have tested the antagonistic potential of PGPRs (Plant growth promoting rhizo- 
bacteria) and have reported a complex response with a range of antagonistic effects on the test pathogens. The use of microbes or their secretions to control plant pathogens offers an attractive alternative for the control of plant diseases [1]. In the present study we have investigated the antagonist activity of some rhizobacteria isolated from mung bean rhizosphere against the F. oxysporum and R. solani.

\section{Materials and Methods}

The two pathogens, Fusarium oxysporum and Rhizoctonia solani were procured from the Department of Plant Pathology, Punjab Agricultural University and were maintained on Potato Dextrose Agar (PDA) slants.

\section{Isolation of rhizobacteria}

Soil samples were randomly obtained from mung bean rhizosphere and standard microbiological procedures were used for rhizobacterial isolation [21]. The colonies were selected, purified on nutrient agar, bacillus agar and pseudomonas agar medium and then transferred to respective slants for further use. For further experiments, the isolates were grown at $30^{\circ} \mathrm{C}$ in respective broths.

Screening of rhizobacteria antagonistic to F. oxysporum and

R. solani

\section{Dual culture test}

The antagonistic activity of 40 rhizobacterial isolates against the pathogenic fungi was evaluated using the dual culture test. In this, $20 \mathrm{ml}$ of sterilized PDA (Potato dextrose agar) was poured into a sterile petri dish and allowed to solidify. After it was cooled, $5 \mathrm{~mm}$ mycelial bit of Fusarium oxysporum and Rhizoctonia solani were inoculated at the centre of two separate plates. Potential antagonistic bacteria were then streaked $3 \mathrm{~cm}$ apart from the fungal inoculum and the plates were incubated at $28^{\circ} \mathrm{C}$ for $48 \mathrm{~h}$ (three replications per culture). Radial growth of the test fungus was measured and percentage growth inhibition was calculated using the equation:

\%Inhibition $=(\mathrm{R}-\mathrm{r}) / \mathrm{R} \times 100$

Where, $r$ is the radius of the fungal colony in the presence of antagonist and $\mathrm{R}$ is the radius of the fungal colony in control [25]. The test was carried out in triplicates.
Elucidation of antagonistic mechanism

Scanning electron microscopy (SEM) of post-interaction events

Small agar pieces $(>1 \mathrm{~cm}$ ) from the zone of interaction (obtained during dual culture assay) were taken out from each plate and transferred to a dried autoclaved vial. The specimen were fixed overnight at $4 \mathrm{C}$ in $2.5 \%$ glutaraldehyde in $0.2 \mathrm{M}$ cacodylate buffer (pH 7.3) followed by three repeated washings (15 minutes each) in cacodylate buffer. Then, $1 \%$ osmium tetra oxide was added and dehydrated by passage through graded aqueous ethyl alcohol series $(30,50,70,90$ and 95\%) and finally placed in 100\% ethanol at room temperature for few minutes. It was then dried, mounted on aluminum stubs and coated with gold-palladium using anion sputtering unit. The samples were then examined under a scanning electron microscope, SEM unit at EMN lab, Punjab Agricultural University, Ludhiana.

Inhibition of fungal growth by diffusibles

The cultures exhibiting the best antagonistic effect in dual culture assay were then co-inoculated with test fungi in $20 \mathrm{ml}$ potato dextrose broth and incubated for a week at $28^{\circ} \mathrm{C}$ under stationary condition and the mycelial mass obtained was then filtered, dried and weighed. Also, all the best antagonists obtained were co-inoculated together with the test fungi. Broth inoculated only with fungal bits served as control. The percentage reduction in dry weight of the mycelial mat (filtered and oven dried at $37^{\circ} \mathrm{C}$ for 30 minutes) was calculated using the equation:

$\%$ Reduction in weight $=(\mathrm{w} 1-\mathrm{w} 2) / \mathrm{w} 1 \mathrm{x} 100$

Where, w1 is the weight of the test fungus in control flask and w2 with bacterial antagonists [26].

Production of diffusible antimetabolites by rhizobacteria was assayed by method of Kumari and Khanna [23].

\section{Volatiles}

Fiddman and Rossal's (1993) sealed plate method was used for testing the production of volatile antimycotic compounds by rhizobacteria. The bacterial lawn of the test bacteria was prepared on nutrient agar medium in a petri-dish and on this was inverted a dish containing PDA inoculated with test fungus (both the test 
fungi). Both were sealed with Para film and incubated at $28^{\circ} \mathrm{C}$. The fungal radial growth of the pathogen was measured regularly for a period of 5 days.

\section{Culture filtrate antibiosis}

For detection of non-volatile antifungal metabolites, selected rhizobacteria were cultured in nutrient broth and incubated at $28^{\circ} \mathrm{C}$ at $200 \mathrm{rpm}$ for 3 days. The culture was centrifuged at 10000 rpm for 20 min and the supernatant was filter sterilized using 0.2 micrometer filter. The supernatants were supplemented in PDA medium @ 50\% i.e. in 2:1 of PDA and supernatant. A piece of actively growing pathogen was placed at the centre of each plate and incubated at $28^{\circ} \mathrm{C}$ for a week. The same volume of sterile distilled water in PDA medium served as control [22].

\section{Hydrolytic enzymes}

For detecting $\beta-1,4$ glucanase, plates containing minimal salt agar medium [23] supplemented with carboxymethyl cellulose $(1 \% \mathrm{w} / \mathrm{v})$ were spot inoculated with rhizobacterial isolates at centre for $48-72 \mathrm{~h}$ at $30^{\circ} \mathrm{C}$. The plates were then flooded with Congo red for $15 \mathrm{~min}$, washed and visualized for CMC hydrolysis.

Similarly, For protease detection, rhizobacterial isolates were spot inoculated on minimum salt agar medium supplemented with casein $(1 \% \mathrm{w} / \mathrm{v})$. The plates were incubated at $28^{\circ} \mathrm{C}$ for $48 \mathrm{~h}$ and were then visualized for zone of hydrolysis.

Production of siderophore

Siderophore production by the rhizobacterial isolates was detected by the method of Schwyn and Neilands [32] using chrome azurol S (CAS). Cultures positive for siderophore produced an orange halo around the colony where siderophores had chelated iron bound to the dye.

Production of HCN and ammonia

The antagonistic isolates were screened for the production of hydrogen cyanide as per the method of Bakker and Schippers [5]. Petri plates encompassing 10\% Trypticase soya agar (TSA) appended with $4.4 \mathrm{~g}$ of glycine per liter were inoculated with bacteria and covered with the lid on which a piece of paper, drenched with $0.5 \%$ picric acid and $2 \%$ sodium carbonate was placed. The plates were then incubated at $30^{\circ} \mathrm{C}$ for $72-96 \mathrm{~h}$. Color change from yellow to orange-brown of the filter paper indicated the presence of HCN.

Bacterial isolates were also tested for the production of ammonia in peptone water [31]. Overnight grown cultures were inoculated into peptone medium and incubated for $2-3$ days at $30^{\circ} \mathrm{C}$. and then $0.5 \mathrm{ml}$ of Nessler's reagent was added. Appearance of a brown to yellow color indicated presence of ammonia.

Phenazine extraction and detection by TLC and HPLC analysis

The rhizobacterial isolates were grown in Pseudomonas broth [8] at $37^{\circ} \mathrm{C}$ for $48 \mathrm{~h}$ for pigment production. Then the pigment rich broth culture was centrifuged at $10000 \mathrm{rpm}$ for $15 \mathrm{~min}$ and the supernatant was collected and acidified with $0.1 \mathrm{~N} \mathrm{HCl}$. The pigment was extracted using benzene (2:1), and the extract was then dried at $37^{\circ} \mathrm{C}$. The residue was then suspended in methanol and the methanol extract was analyzed by TLC using methanol and chloroform solvent (in 1:1) system. The plates were visualized under UV-light and Rf values recorded [29].

The production of phenazine was further detected by reverse phase chromatography was performed using a Varian HPLC system fitted with Lichrosphere RP18 column (Merck KgaA, Darmstadt, Germany) to confirm the presence of phenazines. The resolution of phenazine was achieved at $325 \mathrm{~nm}$ under isocratic conditions at a flow rate of $1.0 \mathrm{ml} \mathrm{min}^{-1}$ using a mobile phase of methanol-water $(60: 40 \mathrm{v} / \mathrm{v})$. A $20 \mu \mathrm{l}$ sample was injected each time for a run of 20 $\min [7]$.

This crude methanol extract was filter sterilized through 0.45 $\mu \mathrm{m}$ pore sized filter and its antagonistic potential was tested against the phytopathogens.

\section{Statistical analysis}

Data was analyzed using Analysis of variance (ANOVA) appropriate for Completely randomized design (CRD) carrying out the statistical analysis using CPCS1 software developed by Department of Mathematics, Statistics and Physics, PAU, Ludhiana.

\section{Results and Discussion \\ Dual culture test (plate assay)}

Twelve out of the 40 isolates showed antagonistic activity against both F. oxysporum and R. solani ranging from $4.44-33.3 \%$ (Table 1) Isolates M01, M032 and M033 displayed strong inhibitory impact on the test fungi (Figure 1). Isolates M032 and M033 exhibited maximum inhibition potential against $F$. oxysporum and $R$. solani, respectively (Table 1).

The inhibition of the fungi (Figure 2) could be a consequence of various allelochemicals- volatiles, diffusibles, HCN, ammonia etc. (Table) produced by these antagonists which are toxic and curtail the phyto-pathogen growth by various mechanisms. 


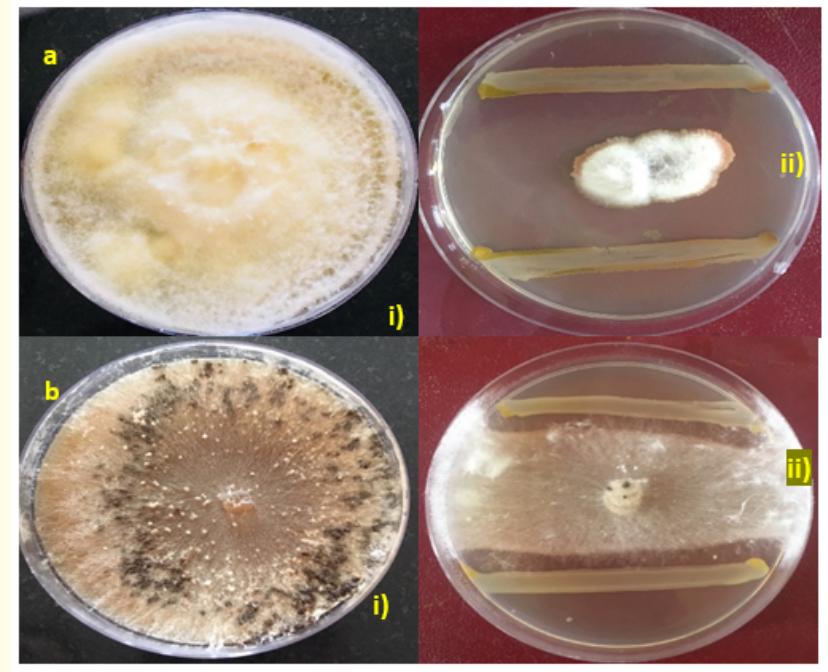

Figure 1: Inhibition of a) Foxysporum i) control ii) inhibition of fungal proliferation and b) R.solani i) control ii) inhibition of fungal proliferation by antagonistic rhizobacteria.

\begin{tabular}{|c|c|c|}
\hline \multirow{2}{*}{$\begin{array}{c}\text { Rhizobacterial } \\
\text { isolates }\end{array}$} & \multicolumn{2}{|c|}{ Inhibition (\%) } \\
\cline { 2 - 3 } & F oxysporum & R. solani \\
\hline M01 & $22.2 \pm 0.14$ & $25.5 \pm 0.74$ \\
\hline M04 & $11.1 \pm 0.12$ & $22.2 \pm 0.98$ \\
\hline M06 & $6.67 \pm 0.49$ & $16.4 \pm 0.87$ \\
\hline M012 & $11.1 \pm 0.51$ & $11.1 \pm 0.12$ \\
\hline M017 & $13.33 \pm 0.24$ & $4.44 \pm 0.89$ \\
\hline M019 & $22.2 \pm 0.38$ & $14.44 \pm 0.26$ \\
\hline M022 & $11.1 \pm 0.44$ & $20 \pm 0.54$ \\
\hline M025 & $16.66 \pm 0.52$ & $27.77 \pm 0.61$ \\
\hline M039 & $13.33 \pm 0.32$ & $22.2 \pm 0.64$ \\
\hline M031 & $11.1 \pm 0.18$ & $21.7 \pm 0.55$ \\
\hline M033 & $28.8 \pm 0.12$ & $33.3 \pm 0.79$ \\
\hline M032 & $33.3 \pm 0.12$ & $28.8 \pm 0.86$ \\
\hline
\end{tabular}

Table 1: Inhibition of phytopathogens in dual plate assay.

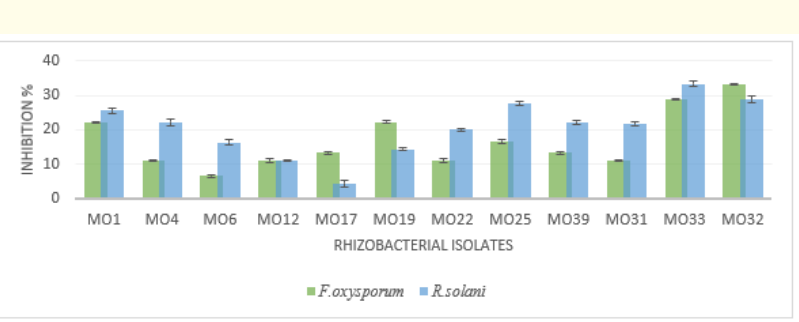

Figure 2: Relative inhibition of F.oxysporum and R.solani by rhizobacteria.

Our studies are consistent with the work of Hanson and Fernandez [10] who reported 45 bacterial isolates to have biocontrol activity against six fungal pathogens. Ji., et al. [12] examined 12 endophytic rhizobacteria for their antagonistic potential against $F$ oxysporum and $R$ solani and found them to be potent antagonists. Studies by Karimi., et al. [17] and Kumari and Khanna [23] also have shown the effectiveness of bacterial strains inhibiting the growth of F. oxysporum f. sp. Ciceris (Foc).

Elucidation of antagonistic mechanism

1. Scanning electron microscopy (SEM) of post-interaction events

The SEM examination of isolate M032 and F. oxysporum and isolate MO33 and R. solani by SEM analysis showed deformities in the hyphae of the respective fungi. The hyphae of $F$. oxysporum (treated with M032) showed (Figure 3) shrinkage with loss of rigidity, deflation and perforations compared with normal hyphae in the control. Also, scanty hyphal growth was pragmatic. Similarly, in case of $R$ solani (Figure 4) (treated with M033) the hyphae were broken or distorted, showing swelling, shrinkage and acerbity.

The SEM studies clearly show the biocidal influence of the culture extracts as depicted by the lysis of mycelial structure.

Our SEM results are in agreement with earlier studies by Agarwal., et al. [1] who evaluated the antagonistic effect of Bacillus MSUA3 against $R$. solani and F. oxysporum using SEM and found the hyphae of F. oxysporum perforated, and lysed. Antimicrobial acti- 
vity of B. amyloliquefaciens FNL13 against F. culmorum Fc1 using SEM by Baffani., et al. [3] and by Kumari and Khanna [22] were also similar.
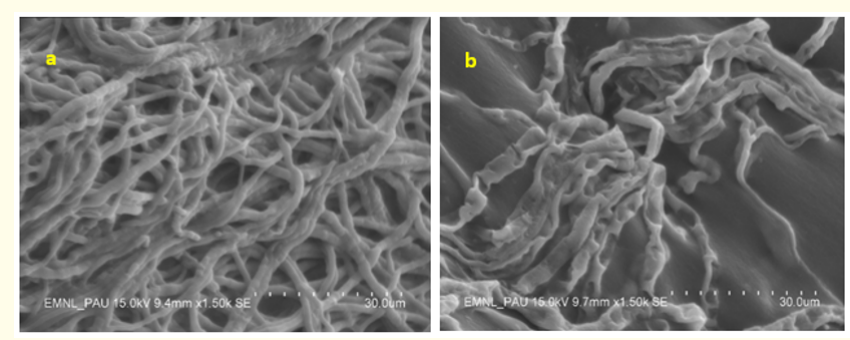

Figure 3: a) Control b) Effects of the antagonistic rhizobacteria MO32 on cell wall integrity of $F$. oxysporum.
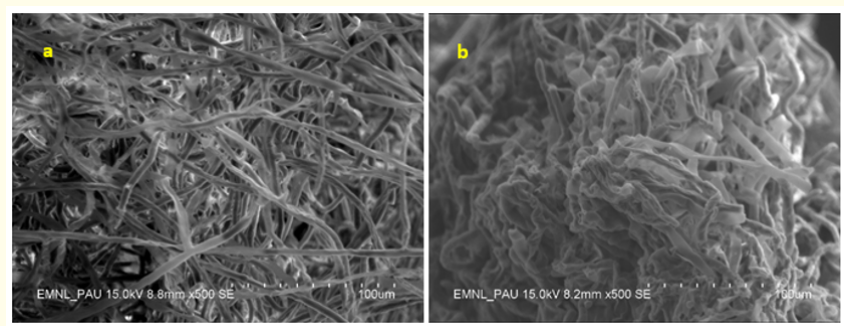

Figure 4: a) Control b) Effects of the antagonistic rhizobacteria M033 on cell wall integrity of $R$. solani.

Inhibition of fungal growth by bacterial diffusibles

Maximum inhibition of fungal growth was by isolate M032 both against F. oxysporum (92\%) and R. solani (84\%) followed by M01 and MO33. The impact of the antagonists on F. oxysporum was more prominent than on $R$. solani, A cumulative inhibiting effect was seen (96 and 92\%) when three rhizo-antagonists were co-inoculated with the phytopathogens respectively, suggesting that the rhizosphere consortia might work as an effective bio-pesticide.

Various diffusibles, volatiles and other anti-metabolites secreted by all the three i.e. M01, M032 and M033, may have acted synergistically to control the pathogenic fungi. Moreover, the twelve antagonistic mung-bean rhizobacteria were adept in the production of diffusible metabolites. The reduction in radial growth of $\mathrm{Fu}$ sarium oxysporum and Rhizoctonia solani after $96 \mathrm{~h}$ established the effect of these anti-metabolites. Growth inhibition varied from 46.2 - 60.6\% among the twelve rhizobacteria, with M032 and M033 displaying comparable inhibition in case of $F$. oxysporum, however in case of R. solani M033 and M01 were at par in inhibiting the pathogen (Table 2). Similar studies by Kumari and Khanna [26] and Kumari., et al. [23] showed the potential of rhizobacterial iso- lates to inhibit $F$. oxysporum and the inhibition percentage elucidated considerable variation $(26.4 \pm 0.72$ to $87.3 \pm 0.10 \%)$. In another study by Kumar., et al. [22] rhizobacterial isolates were also found to exhibit antagonistic activity ranging from $79.8-84.4 \%$ against $F$. oxysporum [2].

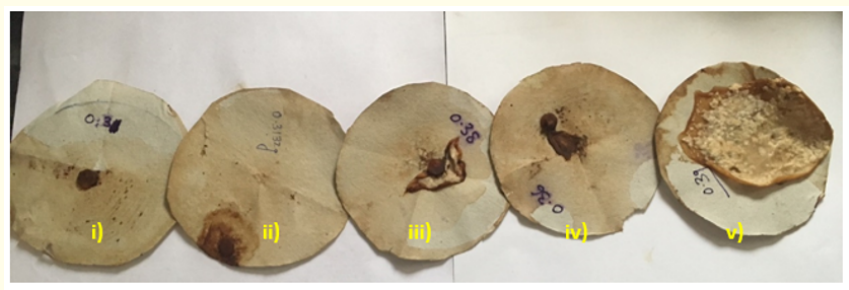

Figure 5: Biomass reduction of R. solani by broth assay clearly depicted. Mycelial mat in presence of i) M01+M032+M033 ii) M033 iii) M01 iv) MO 32 v) control.

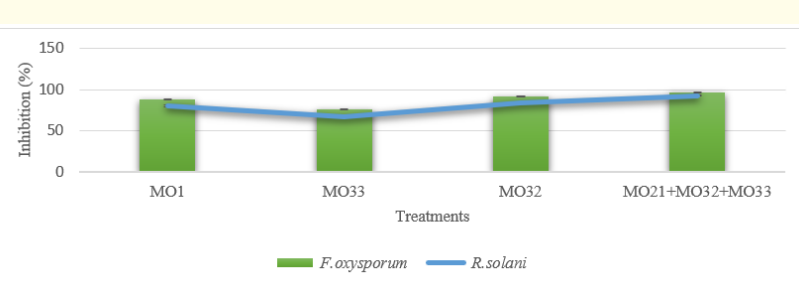

Figure 6: Inhibition of mycelial proliferation (in broth assay).

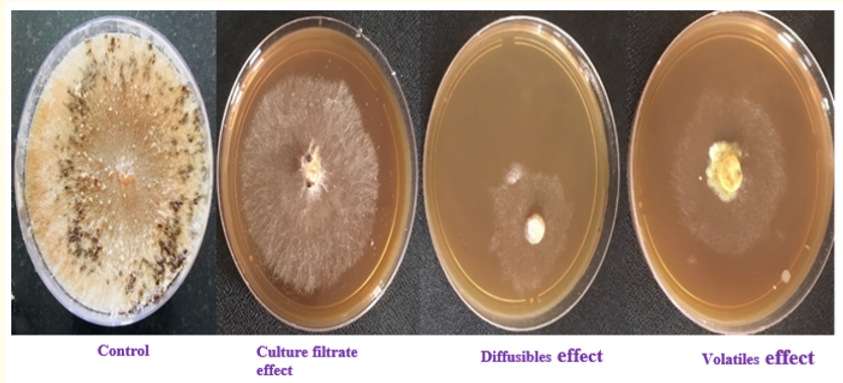

Figure 7: Inhibition of R. solani by diffusibles, volatiles etc. secreted by rhizobacteria isolate M033.

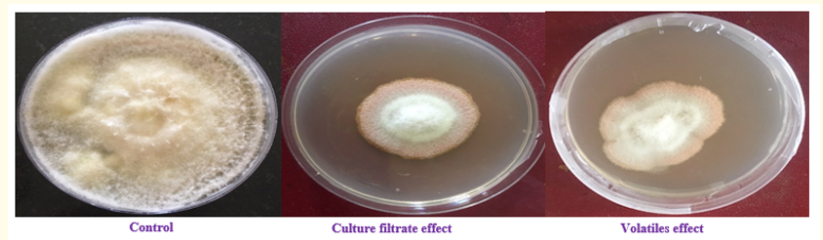

Figure 8: Inhibition of F. oxysporum by diffusibles, volatiles etc. secreted by rhizobacterial isolate M032. 


\begin{tabular}{|l|c|c|c|c|c|c|}
\hline \multirow{2}{*}{$\begin{array}{l}\text { Rhizobacterial } \\
\text { isolates }\end{array}$} & \multicolumn{3}{|c|}{ R solani Inhibition (\%) } & \multicolumn{2}{c|}{ Foxysporum Inhibition (\%) } \\
\cline { 2 - 7 } & Diffusibles & VACs & Filtrates & Diffusibles & VACs & Filtrates \\
\hline M01 & $60.0 \pm 0.83$ & $56.8 \pm 0.25$ & $59.3 \pm 0.14$ & $56.25 \pm 0.147$ & $55.625 \pm 0.627$ & $59.37 \pm 0.823$ \\
\hline M04 & $47.5 \pm 0.71$ & $40.0 \pm 0.35$ & $57.5 \pm 0.24$ & $50.00 \pm 0.248$ & $42.50 \pm 0.847$ & $62.50 \pm 0.146$ \\
\hline M06 & $53.7 \pm 0.94$ & $38.7 \pm 0.30$ & $55.0 \pm 0.54$ & $56.25 \pm 0.147$ & $37.25 \pm 0.604$ & $56.25 \pm 0.894$ \\
\hline M017 & $58.7 \pm 0.14$ & $26.2 \pm 0.28$ & $57.5 \pm 0.32$ & $58.75 \pm 0.341$ & $30.00 \pm 0.494$ & $58.75 \pm 0.646$ \\
\hline M019 & $46.2 \pm 0.65$ & $38.7 \pm 0.15$ & $61.2 \pm 0.85$ & $46.25 \pm 0.644$ & $40.00 \pm 0.348$ & $61.25 \pm 0.848$ \\
\hline M022 & $51.2 \pm 0.43$ & $33.7 \pm 0.44$ & $50.0 \pm 0.64$ & $50.00 \pm 0.794$ & $35.00 \pm 0.148$ & $51.25 \pm 0.146$ \\
\hline M025 & $52.5 \pm 0.59$ & $27.5 \pm 0.58$ & $57.5 \pm 0.70$ & $55.00 \pm 0.249$ & $27.50 \pm 0.594$ & $60.00 \pm 0.147$ \\
\hline M031 & $50.0 \pm 0.94$ & $27.5 \pm 0.85$ & $63.7 \pm 0.85$ & $51.25 \pm 0.145$ & $31.37 \pm 0.892$ & $65.00 \pm 0.697$ \\
\hline M032 & $51.2 \pm 0.76$ & $43.7 \pm 0.74$ & $58.7 \pm 0.54$ & $55.00 \pm 0.540$ & $35.00 \pm 0.994$ & $62.50 \pm 0.890$ \\
\hline M033 & $55.0 \pm 0.64$ & $55.0 \pm 0.91$ & $82.5 \pm 0.59$ & $60.625 \pm 0.746$ & $47.50 \pm 0.476$ & $81.25 \pm 0.447$ \\
\hline M039 & $61.8 \pm 0.89$ & $43.7 \pm 0.56$ & $67.5 \pm 0.60$ & $60.00 \pm 0.194$ & $55.00 \pm 0.894$ & $66.25 \pm 0.194$ \\
\hline
\end{tabular}

Table 2: \% Inhibition of phytopathogens by various antifungal metabolites.

Volatile antifungal compounds (VAC)

Volatile compounds such as alkanes, aldehydes, ammonia, esters, ketones, sulfides and terpenoids produced by some rhizobacteria are known to exhibit antifungal activity against phytopathogens. Certain volatile antifungal compounds are known to be effective against $F$. oxysporum and $R$. solani. In the current study substantial reduction in the growth of the pathogen in the presence of VACs was observed (Table 2). The growth inhibition by VAC varied between $26.2-56.8 \%$ against both the pathogens.

Similar antifungal activity by volatile organic compounds of rhizobacteria has been reported as an antagonistic armor against phytopathogens by Kumari., et al. [24]. Eleven isolates from chickpea rhizosphere were capable of inhibiting $F$ oxysporum $f$. sp. ciceris, with maximum inhibition by Ps-14c (39.4\%). About $65.7 \%$ of the rhizobacterial antagonists were reported to produce antifungal volatile compounds as apparent from the decrease in growth of Rhizoctonia sp.in sealed plate technique with inhibition varying between 27.6 and $66.6 \%$ [18].

Culture filtrate antibiosis

Three days old culture filtrates of the mung bean rhizobacterial isolates displayed inhibitory to growth of both the test pathogens i.e. $F$ oxysporum and $R$. solani. The percentage inhibition ranged from 51.25 t0 $81.25 \%$ with former and $50-80.25 \%$ with the later.
This test basically confirms the production of certain non-volatile antimycotic elements by the antagonistic rhizobacteria. Similar to this study, Kumari., et al. [23] also reported that three days old culture filtrates of the bacterial antagonists inhibited the growth of Rhizoctonia sp.in the range of 13.3-71.75\%. Mishra., et al. [27] also found four days old culture filtrate of $B$. subtilis MA-2 completely inhibiting the growth of Alternaria alternata and Curvularia andropogonis.

\section{Production of glucanase and protease}

Biocontrol agents are known to produce number of hydrolytic enzymes including glucanases, proteases [14] etc.

Production of hydrolytic enzymes by PGPR is an important mechanism used against phytopathogens helping in sustainable plant disease management. These enzymes break down the cell wall of fungal pathogens leading to cell death [14]. Karimi., et al. [15] demonstrated production of proteases and $\beta-1,4$ glucanase by the antagonistic rhizobacterial isolates from the chickpea rhizosphere, which is similar to results reported herein.

\section{Production of siderophore}

All of the twelve potent rhizobacterial antagonist showed a distinct orange halo on CAS plates indicating siderophore production. The orange halos diameter ranged from $12-40 \mathrm{~mm}$, where the ha- 
lo-zone was observable after $72 \mathrm{hrs}$ of incubation, with maximum diameter observed on $15^{\text {th }}$ day of incubation. The maximum diameter observed was $40 \mathrm{~mm}$ (for M032). Also, the biocontrol agents possessed the ability to produce both type of siderophores, however, catechol type siderophore was produced in higher amounts compared to the Hydroxamate type.
Kumari., et al. [23] reported siderophore production index ranging from $6 \mathrm{~mm}$ to $28.6 \mathrm{~mm}$ by rhizobacteria isolated from chick pea rhizosphere. Gupta and Gopal [11] also examined ten rhizobacteria isolated for siderophore production and found six of them positive with diameter of the orange halos ranging from 6.7 to $46 \mathrm{~mm}$.

\begin{tabular}{|c|c|c|c|c|c|}
\hline $\begin{array}{c}\text { Rhizobacterial } \\
\text { isolates }\end{array}$ & $\begin{array}{c}\text { Siderophore } \\
\text { production (mm) }\end{array}$ & $\begin{array}{c}\text { HCN } \\
\text { Production }\end{array}$ & $\begin{array}{c}\mathbf{N H}_{3} \\
\text { Production }\end{array}$ & $\begin{array}{c}\text { Glucanase } \\
\text { production }\end{array}$ & $\begin{array}{c}\text { Protease } \\
\text { production }\end{array}$ \\
\hline M01 & 36 & + & +++ & + & + \\
\hline M04 & 28 & + & +++ & - & + \\
\hline M06 & 32 & - & + & + & + \\
\hline M012 & 29 & - & + & + & + \\
\hline M017 & 24 & + & +++ & + & + \\
\hline M019 & 14 & + & + & + & + \\
\hline M022 & 25 & - & +++ & + & + \\
\hline M025 & 12 & + & + & + & + \\
\hline M031 & 26 & + & +++ & + & + \\
\hline M032 & 40 & + & + & + & + \\
\hline M033 & 38 & - & + & + & + \\
\hline M039 & 30 & & + & + & + \\
\hline
\end{tabular}

Table 3: Antimetabolite profile of biocidal rhizobacterial isolates.

\section{Production of HCN and ammonia}

HCN and ammonia are chemicals produced by rhizobacteria and are known to have inhibitory effect on the growth of phytopathogens. The bacterial isolates showed moderate to considerable cyanogenesis and ammonia production. Among these, M01, M032, M025, M033 and M031 were high HCN and ammonia producers. These results are similar to the study by Kremer and Souissi [17] who found that $32 \%$ of total 2000 rhizobacterial isolates were cyanogenic. In another work [11] four among the ten $P$ fluoresens strains were strong HCN producers while the remaining six were moderate producers [11]. Dastager., et al. [6] found Micrococcus sp N11-0909 isolated from cowpea rhizosphere to be a strong ammonia producer. Kumar., et al. [20] tested ten strains of Pseudomonas from chickpea rhizosphere and reported ammonia production by them.

Phenazine extraction and detection by TLC and HPLC analysis

Phenazines are heterocyclic secondary metabolites possessing antibiotic properties. Phenazine - 1- carboxylic acid (PCA) is pro- duced by fluorescent pseudomonads. M032 and M033 two rhizobacteria manifesting, the characteristic fluorescent pigmentation were analyzed for Phenazine production. Our results (Figure 9) in compliance with studies by Devnath., et al. [9] and Alagwadi., et al. [3] who reported Rf value for phenazine ranging from $0.70-0.85$.
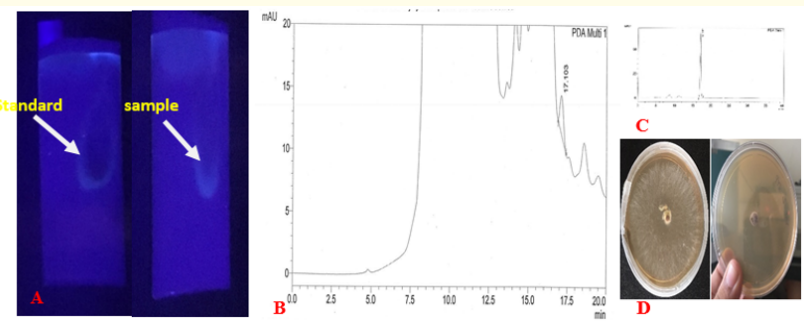

Figure 9: A) TLC analysis showing spots corresponding to standard (left) and the sample (right) B) HPLC analysis indicating 17.03 min retention time C) PCA standard HPLC chromatogram D) Anti-fungal effect of crude extract after 96 hours of incubation (left) control (right) fungal inhibition in presence of crude extract. 
The phenazine (i.e PCA) present in rhizobacteria is known to impart strong antifungal ability. They uually act by stimulating the induced systematic pathway in plants which leads to disease supression. Not only phenazine production imparts them biocidal activity but also helpd them toperpetuate in rhizosphere.

HPLC analysis carried out supported TLC results for M033 but no peak was detected in case of M032. The Phenazine level in M032, therefore, was below detection level. The retention time recorded was 17.03 min for sample compared to 17.1 for the standard, clearly depicting presence of the metabolite phenazine. The amount of PCA produced was $5.6 \mu \mathrm{g} / \mathrm{ml}$. The methanolic extract depicted a strong antifungal activity (Figure 9). Similar results were obtained by Kavitha., et al. [19] who reported a broad spectrum of phenazines produced by Pseudomonas genera.

\section{Conclusions}

The rhizobacterial isolates clearly depict their ability to produce various metabolites as hydrogen cyanide production, siderophores, ammonia and various diffusibles. The HPLC analysis and other biochemical tests confirms their presence and the inhibitory effect of these metabolites is clearly elucidated in the present studies. Also, the inhibition of both the test pathogens by the crude methanol extract strengthens our results. Thus, it can be said that the secondary metabolites detected in rhizobacteria contribute towards their biocidal potential against both the phytopathogens, thereby, advocating the scope of these rhizobacteria as potent bio-pesticides which will be prolific substitute to the chemicals used these days.

\section{Bibliography}

1. Agarwal M., et al. "Differential antagonistic responses of Bacillus pumilus MSUA3 against Rhizoctonia solani and Fusarium oxysporum causing fungal diseases in Fagopyrum esculentum Moench". Microbiological Research 205 (2017): 40-47.

2. Agbodjato NA., et al. "Characterization of Potential Plant Growth Promoting Rhizobacteria Isolated from Maize (Zea mays L.) in Central and Northern Benin (West Africa)". Applied and Environmental Soil Science 10 (2015): 01-10.

3. Alagawadi AR., et al. "In vitro antagonistic activity and phylogeny of plant growth-promoting bacteria native to Western ghats of Karnataka, India". Journal of Pharmacognosy and Phytochemistry 6 (2017): 786-792.
4. Baffoni L., et al. "Microbial inoculants for the biocontrol of Fusarium spp. in durum wheat". BMC Microbiology 15 (2015): 242.

5. Bakker AW and Schippers B. "Microbial cyanide production in the rhizosphere in relation to potato yield reduction and Pseudomonas spp. Mediated plant growth stimulation". Soil Biology Biochemistry 19.4 (1987): 249-256.

6. Beneduzi A., et al. "Plant growth-promoting rhizobacteria (PGPR): Their potential as antagonists and biocontrol agents". Genetics and Molecular Biology 35.4 (2012): 1044-1051.

7. Dastager SG., et al. "Isolation and characterization of novel plant growth promoting Micrococcus sp NII-0909 and its interaction with cowpea". Plant Physiology and Biochemistry 48.12 (2010): 987-992.

8. Devnath P., et al. "Extraction, purification and characterization of pyocyanin produced by Pseudomonas aeruginosa and evaluation of its antimicrobial activity". International Research Journal of Biological Sciences 6.5 (2017): 01-09.

9. Dinesh R., et al. "Isolation, characterization, and evaluation of multi- trait plant growth promoting rhizobacteria for their growth promoting and disease suppressing effects on ginger". Microbiological Research 173 (2015): 34-43.

10. Fiddman PJ and Rossall S. "The production of antifungal volatiles by Bacillus subtilis". Journal of Applied Microbiology 74.2 (1993): 119-126.

11. Goswami D., et al. "Screening of PGPRs from saline desert of kutch: Growth promotion in Arachis hypogea by Bacillus licheniformis A2". Microbiological Research 169 (2014): 66-75.

12. Gupta A and Gopal M. "Siderophore production by plant growth promoting rhizobacteria". Indian Journal of Agricultural Research 42 (2008): 153-156.

13. Hanson KG and Fernandez MR. "Evaluation of bacterial strains for control of Fusarium graminearum and other cereal pathogens" (2002).

14. Hyedaril, S., et al. "Hydrogen Cyanide Production Ability by Pseudomonas Fluorescence Bacteria and their Inhibition Potential on Weed Germination" (2008).

15. Jadhav HP and Sayyed RZ. “Hydrolytic Enzymes of Rhizospheric Microbes in Crop Protection". MOJ Cell Science and Report 3 (2016): 01-02. 
16. Jadhav HP., et al. "Role of Hydrolytic Enzymes of Rhizoflora in Biocontrol of Fungal Phytopathogens: An Overview". Rhizotrophs: Plant Growth Promotion to Bioremediation 3 (2017): 183-205.

17. Ji SH., et al. "Isolation and characterization of plant growth promoting endophytic diazotrophic bacteria from Korean rice cultivars". Microbiological Research 169.1 (2014): 83-98.

18. Karimi K., et al. "Evaluation of biocontrol potential of Pseudomonas and Bacillus spp. against Fusarium wilt of chickpea". Australian Journal of Crop Science 6 (2012): 695-703.

19. Kaur G and Khanna V. "Effect of Rhizobium and temperature tolerant plant growth promoting rhizobacteria on yield of pigeon pea (Cajanus cajan L.) MSc thesis". Punjab Agricultural University, Ludhiana (2011).

20. Kavitha K., et al. "Broad spectrum action of phenazine against active and dormant structures of fungal pathogens and root knot nematode". Archives of Phytopathology and Plant Protection 38.1 (2005): 69-76.

21. Kremer RJ and Souissi T. "Cyanide Production by Rhizobacteria and Potential for Suppression of Weed Seedling Growth". Current Microbiology 43.3 (2001): 182-186.

22. Kumar A., et al. "Isolation, screening and characterization of bacteria from Rhizospheric soils for different plant growth promotion (PGP) activities: an in vitro study". Recent Research in Science and Technology 4 (2012): 01-05.

23. Kumari P and Khanna V. "Allelopathic effects of native Bacillus sp. against Fusarium oxysporum causing chickpea wilt". Allelopathy Journal 38.1 (2016): 77-90.

24. Kumari P., et al. "Multifaceted rhizobacteria mediated growth augmentation in chickpea". Agricultural Research 6 (2017): 368-377.

25. Kumari P., et al. "Metabolites in control of Rhizoctonia bataicola". Journal of Pure Applied Microbiology 9 (2016): 749-756.

26. Kumari S and Khanna V. "Effect of antagonistic coinoculated with Mizorhizobium ciceris on control of fusarium wilt in chickpea (Cicer arietinum L.). African Journal of Microbiology Research 8 (2014): 1255-1265.
27. Kumari S and Khanna V. "Biological Management of Vascular Wilt of Chickpea (Cicer arietinum L.) Incited by Fusarium oxysporum f. sp. ciceris by Antagonistic Rhizobacteria Co-Inoculated with Native Mesorhizobium". International Journal of Current Microbiology and Applied sciences 7 (2018): 920-941.

28. Mishra RK., et al. "Culture filtrate antibiosis of PGPRs against phytopathogens infecting medicinal and aromatic plants". International Journal of Research and Biological Sciences 1 (2011): 45-51.

29. Montealegre JR., et al. "Selection of 3 bio antagonistic bacteria to be used in biological control of Rhizoctonia solani in tomato". Electronic Journal of Biotechnology 6.2 (2003): 116-127.

30. Padaria JC., et al. "Identification of phenazine -10 carboxylic acid gene (phc CD) from Bacillus pumilus MTCC7615 and its role in antagonism against Rhizoctonia solani". Journal of Baic Microbiology 56.9 (2016): 999-1008.

31. Ramzan N., et al. "Effect of seed pelleting with biocontrol agents on growth and colonization of roots of mung bean by root-infecting fungi". Journal of the Science of Food and Agriculture 96.11 (2016): 3694-3700.

32. Saraf M., et al. "Role of allelochemicals in plant growth promoting rhizobacteria for biocontrol of phytopathogens". Microbiological Research 169.1 (2014): 18-29.

33. Schwyn B and Neilands J.B. "Universal chemical assay for the detection and determination of siderophore". Annals of Biochemistry 160.1 (1987): 47-56.

34. Sharma P., et al. "Potential of ACC-deaminase producing plant growth promoting rhizobacteria on water stress mitigation in lentil (Lens culinaris L. Medikus) under axenic conditions". International Journal of Advanced Research 3 (2015): 59-67.

35. Singh J., et al. "Current status of web blight of mung bean". Asian Journal of Soil Science 8 (2013): 495-505.

36. Syamala M and Sivaji M. "Functional characterization of various plant growth promoting activity of Pseudomonas fluoresensand Bacillus subtilis from Aloe vera rhizosphere". Journal of Pharmacognosy and Pharmachemistry 6 (2017): 120-122.

\section{Volume 2 Issue 8 August 2019 C) All rights are reserved by $M$ Oberai and V Khanna.}

